\title{
Bioavailability of Pentoxifylline-Chitosan Oral Matrix Tablet in Healthy Subjects
}

\author{
Zeynep S. Teksin', Ilbeyi Agabeyoglu“* and Kadri Yamac ${ }^{2}$
}

${ }^{1}$ Gazi University, Faculty of Pharmacy, Department of Pharmaceutical Technology, Ankara 06330 Turkey ${ }^{2}$ Gazi University, Faculty of Medicine, Hematology Unit, Ankara, TURKEY

\begin{abstract}
Pentoxifylline (PX) is a highly water-soluble, hemorheologic drug that undergoes first-pass effect with $20 \%$ bioavailability. Chitosan $(\mathrm{CH})$, a biocompatible and biodegradable natural polymer, is used to increase drug bioavailability, as well as prolonging release. The aim of this study was to investigate the feasibility of enhancement of oral bioavailability of PX using $\mathrm{CH}$. $\mathrm{CH}$ was used as an absorption enhancer for preparing the matrix tablet. The in vitro release and bioavailability of $\mathrm{PX}-\mathrm{CH}$ tablet was compared with the reference product (Trental ${ }^{\circledR}-400$, Sanofi-Aventis, Turkey). PX-CH tablets were prepared by the slugging method. The in vitro release studies were performed by a flow-through cell apparatus (USP Apparatus IV). A randomized, two-way crossover bioavailability study was conducted in 12 fasting, healthy male volunteers to compare PX-CH and reference tablets; both of them containing $400 \mathrm{mg}$ PX. One tablet of either formulation was administered after a $12 \mathrm{~h}$ overnight fast. After dosing, serial blood samples were collected during a period of 12 hours. Plasma samples were analyzed for PX by a validated UV-HPLC method. The pharmacokinetic parameters $\mathrm{AUC}_{0-12}, \mathrm{AUC}_{0 \text {-inf, }}, \mathrm{C}_{\text {max }}, \mathrm{t}_{\text {max }}, \lambda_{\mathrm{z}}, \mathrm{t}_{1 / 2}, \mathrm{Vd}$ and CL were determined from plasma concentration-time profiles for both formulations. A higher in vitro release rate of PX was observed using acidic dissolution medium. The total in vitro release of PX was $104 \%$ for PX-CH and $78.7 \%$ for the reference after 12 hours. The mean maximum plasma concentration $\left(\mathrm{C}_{\max }\right)$ of PX-CH tablets was $1260 \pm 910 \mathrm{ng} / \mathrm{mL}$ after a $\mathrm{t}_{\max }$ of $0.784 \pm 0.406 \mathrm{~h}$. For the reference, they were $67.9 \pm 33.7 \mathrm{ng} / \mathrm{mL}$ and a $\mathrm{t}_{\text {max }}$ of $1.48 \pm 0.79 \mathrm{~h}$, respectively. It was found that the relative bioavailability of PTX was significantly increased with $\mathrm{CH}$, compared to reference. $\mathrm{AUC}_{0 \text {-inf }}$ values for test and reference were $1740 \pm 850 \mathrm{ng}$.h/ $\mathrm{mL}$ and $1270 \pm 780 \mathrm{ng} . \mathrm{h} / \mathrm{mL}$, respectively. Enhancement of the bioavailability of PX would suggest that $\mathrm{CH}$ could be used to improve oral bioavailability of PX.
\end{abstract}

Keywords: Pentoxifylline; Chitosan; Bioavailability; Noncompartmental Pharmacokinetics; Tablet

\section{Introduction}

Currently, the oral route is still regarded as the most convenient route of drug absorption. Many drugs experience low bioavailability after oral administration due to poor absorption or susceptibility to first pass metabolism. Absorption enhancers are capable of improving the absorption of low bioavailable drugs. Some absorption enhancers specifically loosen tight junctions and enhance transport/absorption. Chitosan $(\mathrm{CH})$ and chitosan salts are among the most well known absorption enhancers (Aungst, 2000; Thanou et al., 2001a; Thanou et al., 2001b). Several reports have been published on the use of chitosan as a tablet excipient; like absorption enhancers to develop oral dosage formulations (Felt et al., 1998; Illum, 1998; Kristl et al., 1993; Kotze et al., 1998a; Kotze et al., 1998b).

Pentoxifylline (PX) (1-[5-oxohexyl]-3,7-dimethylxantine) (CAS-6493-05-6) is an orally active hemorheological drug for the treatment of intermittent claudication or other circulatory disorders. Its hemorheological effects include reduction of blood viscosity and increasing erythrocyte deformability (Ward et al., 1987). PX is a highly water-soluble drug $(\sim 77 \mathrm{mg} / \mathrm{mL})$. It is well absorbed from the gastrointestinal tract ( $>95 \%)$, yet the actual amount of drug bioavailable to the body is only about 20 $\%$ because of extensive hepatic first-pass metabolism. PX is hepatically metabolized by hydroxylation and demethylation to six renally excreted metabolites. Hydroxy-PX is one of the major metabolites in the plasma (Smith et al., 1986). Administration of a single dose of PX $(400 \mathrm{mg})$ extended-release tablets resulted in $\mathrm{t}_{\max }$ values of 2-4 hours and $\mathrm{C}_{\max }$ 's of $55-300 \mathrm{ng} / \mathrm{mL}$ (Beerman et al., 1985). Since PX has a short half-life (about 0.4-0.8 h), frequent dosing is necessary to maintain therapeutic plasma levels.

In recent years, chitosan $(\mathrm{CH})$ and its salts have attracted much attention as a potential absorption enhancer across mucosal epithelia, especially for low bioavailability drugs. $\mathrm{CH}$ is regarded as a biocompatible, biodegradable, natural origin polymer and is widely used in food and pharmaceutical industry (Kumar, 1998). It is used to prepare controlled or immediate release of drugs as a pharmaceutical adjuvant. It can increase drug bioavailability, as well as prolong the release (Nigalaye et al., 1990). Its enhancer activity on the buccal, nasal, rectal and intestinal mucosa and transdermal transport have been well documented (Aspden et al., 1996; Degim et al., 2003; Senel et al., 2000). The enhancing capability of $\mathrm{CH}$ is thought to be respon-

*Correspondence author: Ilbeyi Agabeyoglu, Gazi University, Faculty of Pharmacy, Department of Pharmaceutical Technology, Etiler, 06330 Ankara, TURKEY, Tel: +90(532)2629939; Fax: +90(312)2127958 ; E-mail: ilbeyi@tr.net

Received September 29, 2009; Accepted October 23, 2009; Published October 23, 2009

Citation: Teksin ZS, Agabeyoglu I, Yamac K (2009) Bioavailability of Pentoxifylline-Chitosan Oral Matrix Tablet in Healthy Subjects. J Bioequiv Availab 1: 115-120. doi:10.4172/jbb.1000018

Copyright: (c) 2009 Teksin ZS, et al. This is an open-access article distributed under the terms of the Creative Commons Attribution License, which permits unrestricted use, distribution, and reproduction in any medium, provided the original author and source are credited. 


\section{Journal of Bioequivalence \& Bioavailability - Open Access}

JBB/Vol.1 November-December 2009

sible for the opening of tight junctions of epithelial cell barriers (Illum, 1998; Kotze et al., 1998a; Kotze et al., 1998b).

In vitro experiments have previously reported that $\mathrm{CH}$ was a suitable agent for the preparation of a prolonged release tablet formulation of PX (Inayatov et al., 1998 ). It was prepared as an oral matrix tablet, using optimum ratio of $\mathrm{CH}$ as an absorption enhancer and was the basis for this work. The aim of this study was to investigate the feasibility of enhancement in oral bioavailability of PX using $\mathrm{CH}$. The in vitro release and relative bioavailability of PX-CH tablets were compared with the reference product (Trental ${ }^{\mathrm{R}}-400$ ), both of them containing $400 \mathrm{mg}$ of PX.

\section{Materials and Methods}

Trental ${ }^{\circledR}$ (serial no: DBC, manufacturing date: 6/1997, expiration date: 6/2002) and pure sample of PX(Sanofi-Aventis, Turkey) and Chitosan H(Dainichiseika Color Chemical Mfg.Co. Ltd., Japan) were kindly supplied by the manufacturers. Avicel $\mathrm{PH} 102^{\mathrm{R}}$ was obtained from F.M.C.Corp. Marcus Hook, USA; magnesium stearate was obtained from Riedel Mannouen, Germany; lactose(Fast-Flo) from HMS Hollandse Melksikerfabriek, Holland and Aerosil 200 was purchased from Degussa, Germany. All other reagents and solvents were of analytical grade of Lab-Scan and Merck(USA).

\section{In Vitro Studies}

\section{Preparation of matrix tablets}

We evaluated the dissolution profiles of various formulation factors to find the optimum ratio of $\mathrm{CH}$. The optimum amount of $\mathrm{CH}$ was found to be $87.5 \mathrm{mg}$ per tablet in our in vitro experiments (Teksin et al., 2000). The in vivo study was conducted in this final formulation.

The matrix tablets of PX were prepared using the slugging method. PX, CH and Avicel PH 102 were passed through a \#45 $(0.350 \mathrm{~mm})$ mesh screen separately and blended for $20 \mathrm{~min}$. The mixture was compacted with an Erweka tablet machine (Korsch-Erweka GmbH, Germany), using a $20 \mathrm{~mm}$ flat-faced punch. Slugged tablets were broken and passed through a \#18 $(1 \mathrm{~mm})$ mesh screen. Aerosil 200 and magnesium stearate were then added and mixed for an additional $5 \mathrm{~min}$. Tablets were compressed with a $12 \mathrm{~mm}$ flat-faced punch. Each tablet (average weight $600 \mathrm{mg}$ ) contained $400 \mathrm{mg}$ of PX. The composition of the matrix tablet is given in Table 1. Lactose and Avicel ${ }^{\mathrm{R}} \mathrm{PH}$ 102 were used as diluents and Aerosil 200 was used as the glidant in a matrix tablet form. Magnesium stearate $(0.75 \% \mathrm{w} / \mathrm{w})$ was then incorporated as the lubricant.

\begin{tabular}{|l|l|}
\hline & \% \\
\hline Pentoxifylline & 66.9 \\
\hline Chitosan & 14.6 \\
\hline Avicel $^{\mathrm{R}}$ PH102 & 4.18 \\
\hline Lactose & 12.6 \\
\hline Aerosil 200 & 0.92 \\
\hline Magnesium stearat & 0.75 \\
\hline
\end{tabular}

Table 1: Formulation of PX matrix tablet (PX-CH).

\section{Physical characteristics of the matrix tablets}

Some physico-pharmaceutical properties of the tablets were also checked, such as weight, diameter, thickness, hardness, friability and content uniformity. Twenty tablets were tested for weight (AB 104, Mettler Toledo, Switzerland), thickness (Vernier Caliper, portable dial hand micrometer, Russia), diametrical crushing strength (CGS, Hardness tester HDT 1V-3, Germany) and friability (Roche friability tester, USA). The mean values were calculated together with standard deviations (SD). The same procedure was carried out for the reference.

The drug content of the tablets was measured by a validated UV-spectrophotometric method. For this purpose, 10 tablets were individually weighted, and then each of them were subjected to dissolution at pH 1.2 in $100 \mathrm{~mL}$ buffer solution. Samples were assayed spectrophotometrically (Beckman DU-600, USA) at 273 $\mathrm{nm}$. The same procedures were carried out with the reference. The results are shown in Table 2.

\begin{tabular}{|l|l|l|}
\hline & Test & Reference \\
\hline Weight $(\mathrm{g})$ & $0.598^{\mathrm{a}} \pm 0.180^{\mathrm{b}}$ & $0.803 \pm 0.282$ \\
\hline Diameter $(\mathrm{cm})$ & $1.20 \pm 0.10$ & $1.78 \pm 0.00$ \\
\hline Thickness $(\mathrm{cm})$ & $0.420 \pm 0.000$ & $0.610 \pm 0.000$ \\
\hline Hardness (kg) & $15.6 \pm 2.1$ & $5.76 \pm 0.39$ \\
\hline Friability (\%) & $0.552 \pm 0.050$ & $\mathrm{NF}^{\mathrm{c}}$ \\
\hline Content Uniformity (\%) & $99.7 \pm 2.0$ & $101 \pm 1$ \\
\hline
\end{tabular}

${ }^{\mathrm{a}}$ Mean, ${ }^{\mathrm{b}}$ Standard deviation (SD), Not friable ${ }^{\mathrm{c}}$

Table 2: The physical characteristics of the tablets.

\section{Swelling studies}

The tablets, put in a wire basket, were lowered into a $50 \mathrm{~mL}$ of $\mathrm{pH} 1.2$ buffer solution and were allowed to swell at $37.0 \pm$ $0.5^{\circ} \mathrm{C}$. They were periodically removed and their changes in weight were measured before and during the swelling. The swelling ratio was then calculated through their weights.

Dissolution experiments, to determine the release of PX under conditions mimicking the gastrointestinal tract, were carried out using a flow-through dissolution apparatus (USP Aparatus IV, Sotax A.G., Switzerland) at a flow rate of $8 \mathrm{~mL} /$ min and fitted with $22 \mathrm{~mm}$ dissolution cells. The tablets were tested for drug release. The dissolution conditions were as follows: $1 \mathrm{~h}$ in $\mathrm{pH} 1.2,1 \mathrm{~h}$ in $\mathrm{pH} 2.5,1.5 \mathrm{~h}$ in $\mathrm{pH} 4.5,1.5 \mathrm{~h}$ in $\mathrm{pH}$ 7.0 and lastly, $7 \mathrm{~h}$ in $\mathrm{pH} 7.5$ in phosphate buffer at $37.0^{\circ} \mathrm{C}$. The flow rate of $8 \mathrm{~mL} / \mathrm{min}$ was chosen to keep the sink conditions during the dissolution test in all dissolution media. The amount of released drug was determined using a UV spectrophotometer (Beckman DU-600) at $273 \mathrm{~nm}$. Experiments were carried out in six parallels. The cumulative percent of drug release was calculated and plotted versus time. Mean data values are presented with the standard deviations (mean $\pm \mathrm{SD}$ ). The same in vitro release tests were also carried out for the reference.

\section{In Vivo Studies}

\section{Subjects and study design}

12 healthy male volunteers, aged between $21-25$ years, weight- 
ing 65-90 kg, with normal clinical findings in hematological and biochemical examinations, participated in the study, after giving the informed consent as defined in the Declaration of Helsinki and under the provisions of EU/ICH. The informed consent protocol was approved by the Ethics Committee of Gazi University Hospital and Master Ethical Committee of Ministry of Health of Turkey. The study was designed as an open label, balanced, randomized 2-period crossover single dose study. A washout period of seven days was enforced between administrations of each treatment.

Subjects were either nonsmokers, or smoked 5-10 cigarettes per day. None had taken any drug and alcohol during the ten days before the study. Subjects were excluded if they were on any planned treatment during until the study, including vitamins and mineral supplements.

\section{Drug sdministration and sampling}

Each subject was administered $400 \mathrm{mg}$ of PX orally as PX$\mathrm{CH}$ and reference with $240 \mathrm{~mL}$ of water, using $2 \mathrm{x} 2$ cross-over model in randomized order, after an overnight fast. The subjects were maintained in the fasting state for $4 \mathrm{~h}$ after administering the drug. Blood samples were collected into heparinized vacuum tubes at $0,0.167,0.333,0.5,0.75,1,1.5,2,2.5,3,4,5$, $6,8,10$ and 12 hours after each dosing. A total of 32 ten $\mathrm{mL}$ blood samples were collected from each subject, during the course of the study through indwelling cannulae placed in forearm veins. After collection, the blood samples were centrifuged at $1.000 \mathrm{~g}$ for $10 \mathrm{~min}$ at room temperature $\left(25^{\circ} \mathrm{C}\right)$; followed by direct transfer into microcentrifuge tubes and stored at $-70^{\circ} \mathrm{C}$ until analysis.

The amount of food and water intake and physical activity for each individual subject were standardized during the sampling day. Xanthine-containing foods or beverages and fruit juice were not allowed for 24 hours before and during the entire sampling days. Blood pressure, heart rate and adverse events were monitored during the blood sampling and also on the follow-up study.

\section{Assay Methodology and Procedure}

\section{Preparation of standard solution and samples for assays}

A stock solution of PX $(40 \mu \mathrm{g} / \mathrm{mL})$ was prepared by dissolving in double distilled water. The working standard solutions of PX were produced by diluting the stock solutions with blank human plasma (1:1). The ten calibration standards of PX were prepared independently. Concentration range of PX was 10 to $2000 \mathrm{ng} / \mathrm{mL}$. All stock solutions, stored at $4^{\circ} \mathrm{C}$, were stable for at least one month without any degradation.

Liquid-liquid extraction method was used for the sample preparation of PX. $0.1 \mathrm{~mL}$ of $1 \mathrm{M}$ sodium hydroxide and $7 \mathrm{~mL}$ of dichloromethane were added to $1 \mathrm{~mL}$ of plasma. The mixture was vortexed for $30 \mathrm{sec}$ and centrifuged at $3000 \mathrm{rpm}$ for 15 min. The upper layer was removed and the organic phase was placed into another test tube and evaporated to dryness under a flow of nitrogen stream at $37^{\circ} \mathrm{C}$. The residue was redissolved in $0.2 \mathrm{~mL}$ of the mobile phase and $30 \mu \mathrm{L}$ of this solution was injected directly on to the column. The plasma extract was stable for at least two days when kept at $4^{\circ} \mathrm{C}$.

\section{Instruments and chromatographic conditions}

The PX concentrations in plasma were assayed using a vali- dated high performance liquid chromatography with ultraviolet detection (UV-HPLC) (Agabeyoglu et al., 2000). A high-performance liquid chromatograph(Hewlett-Packard Series 1050) was equipped with a variable wavelength UV detector. The analytical column was a reverse phase, 300 x 3.9 mm I.D., RP-18 $\mu \mathrm{m}$ Hyperbond(Hypersil). The detection was at $273 \mathrm{~nm}$. The mobile phase was a mixture of methanol:water $(58: 42, \mathrm{v} / \mathrm{v})$ and the flow rate was $1 \mathrm{~mL} / \mathrm{min}$.

Retention time of PX was 5.15 min (retention volume 5.15 $\mathrm{mL}$ ). The bioanalytical method was specific with no interfering impurities at the retention time of PX. Linear calibration model was constructed between peak-height and concentration of PX in plasma samples. Using peak height between day and withinday precisions expressed as $\mathrm{CV} \%$ were smaller (in the range of 4-7\%) than using peak area between day and within-day precisions (in the range of 5-9\%) to quantitate. Therefore, peak height was preferred. The method exhibited linearity of response over a range of $10-2000 \mathrm{ng} / \mathrm{mL}$ for $\mathrm{PX}\left(\mathrm{r}^{2}=0.998\right)$. Limit of detection and limit of quantification were found to be 5 and $10 \mathrm{ng} / \mathrm{mL}$, respectively.

Quality control samples at three levels, low $(30 \mathrm{ng} / \mathrm{mL})$, middle $(600 \mathrm{ng} / \mathrm{mL})$ and high $(1600 \mathrm{ng} / \mathrm{mL})$ for PX were used during routine analysis. The within-batch precision ranged from 2.30 to $5.35 \%$ and accuracy ranged 99.6 to $103 \%$. The betweenbatch precision and accuracy ranged from 4.43 to 6.85 and 102 to $105 \%$, respectively.

The stability of the samples under frozen conditions, at room temperature, and during freeze-thaw cycle were also determined. The accuracy and precision for calibration curve standards and quality samples in all bioanalytical methods met the acceptance criteria as per FDA guideline.

\section{Pharmacokinetic Evaluation}

Non-compartmental modeling was used to estimate PX pharmacokinetic parameters after single dose administration. The PX plasma concentration-time data were evaluated using the nonlinear regression program WinNonlin ${ }^{\mathrm{TM}}$ (Pharsight Corp., Mountainview, CA; version 4.1). Pharmacokinetic parameters $\mathrm{C}_{\max }$ (maximum $\mathrm{PX}$ concentration), $\mathrm{t}_{\max }$ (the time that $\mathrm{C}_{\max }$ occurred), $\mathrm{AUC}_{0-12}$ (area under the plasma concentration time curve from 0 up to $12 \mathrm{~h}$ ), $\mathrm{AUC}_{0 \text {-inf }}$ (area under the plasma concentration time curve from 0 up to infinity), $\lambda_{\mathrm{z}}$ (elimination rate constant), $\mathrm{t}_{1 / 2}$ (half-life), $\mathrm{V}_{\mathrm{d}}$ (distribution volume), and $\mathrm{Cl}$ (clearance) were determined using non-compartmental analysis. The $\mathrm{AUC}_{0 \text {-inf }}$ for plasma was determined by the linear trapezoidal rule.

\section{Results}

\section{Evaluation of In Vitro Studies}

Both tablet formulations were evaluated from the point of view of the physical properties of the tablets (Table 2) and their in vitro releases. The crushing forces for the test and reference tablets were found to be $15.6 \pm 2.1 \mathrm{~kg}$ and $5.76 \pm 0.39 \mathrm{~kg}$, respectively. The reference was not friable because it is a film-coated tablet. The mean drug content of the PX tablets were found to be in the range of $399 \pm 2$ and $402 \pm 1 \mathrm{mg}$ for test and reference, respectively. This indicated that, the tablets passed the content uniformity test as they contained 99.7-101\%. In all determina- 


\section{Journal of Bioequivalence \& Bioavailability - Open Access}

JBB/Vol.1 November-December 2009

tions, test and reference tablets were found to be within pharmacopeial limits. The effect of $\mathrm{pH}$ on the swelling process of $\mathrm{CH}$ was important, as it started immediately on contact with the gastric fluid. In vitro experiments have shown that $\mathrm{PX}-\mathrm{CH}$ readily formed a gel at $\mathrm{pH} 1.2$ (simulated gastric fluid), but showed poor gel-forming abilities at higher $\mathrm{pHs}$. The tablets did not disintegrate for two hours at $\mathrm{pH}$ 1.2. The investigation of the tablet swelling properties was performed at $\mathrm{pH} 1.2 .115$ $\%$ swelling was observed after the first 15 minutes. Maximum was $175 \%$ after 75 minutes. A gel layer was observed around the tablets at early stages at $\mathrm{pH} \mathrm{1.2,} \mathrm{but} \mathrm{this} \mathrm{layer} \mathrm{started} \mathrm{to}$ diminish as the $\mathrm{pH}$ was increased. This observation indicated that the gel-forming ability of $\mathrm{CH}$ can be seen only at low pHs.

The release profiles of test and reference were investigated using the flow-through dissolution method. Flow-through cell apparatus was used, since it was thought that in vivo gastrointestinal transit conditions may best be imitated by such an apparatus, using different, but sequential $\mathrm{pH}$ media. Five different media, namely $\mathrm{pH} 1.2,2.5,4.5,7$ and 7.5 were used for the release studies. The in vitro release profiles are shown in Figure 1. As can be seen, the test tablet showed a higher drug release between 5 and $12 \mathrm{~h}$ at $\mathrm{pH} 7.0$ and 7.4, compared with reference, whereas the release of drug was found to be almost identical for the first $5 \mathrm{~h}$ at low $\mathrm{pHs}$. When the in vitro release profiles were compared, the test tablet was significantly different from the reference $(\mathrm{p}<0.05)$. The total release of PX was experimentally determined to be $102 \%$ for $\mathrm{PX}-\mathrm{CH}$ and $78.7 \%$ for the reference after 12 hours. It was observed that the $\mathrm{CH}$ in the matrices played an important role in acidic media, because of the gelforming ability for prolonged release, which retards the drug diffusion from the tablet. However, in basic media, the drug release increased due to diminishing gel layer. All results indicated that $\mathrm{CH}$ affected the PX release from the matrix tablet.

\section{Evaluation of In Vivo Studies}

The plasma PX concentrations were followed throughout 12 hrs after the administration of the two PX formulations in 12

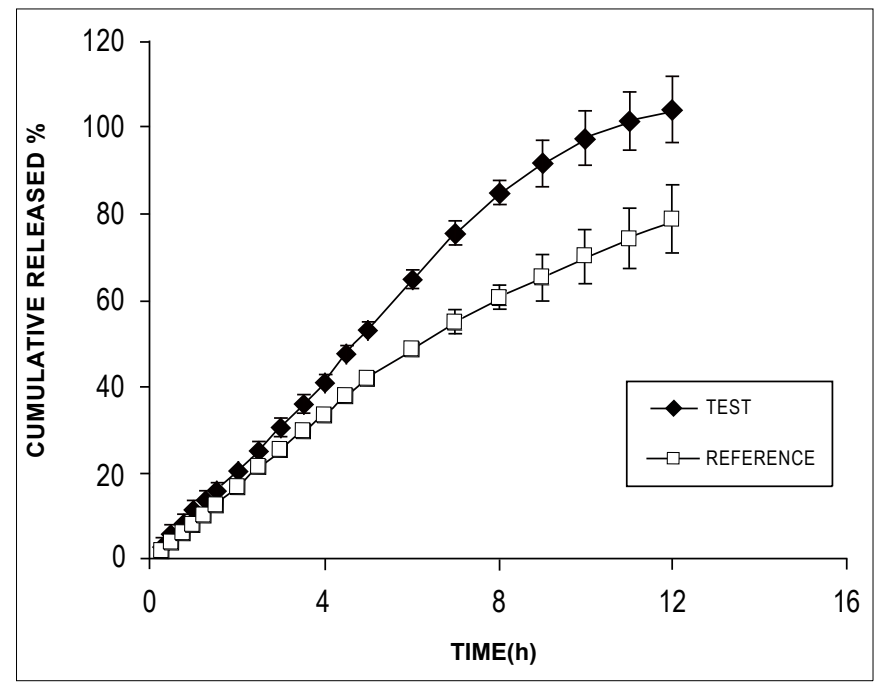

Figure 1: healthy male subjects. The PX concentrations in plasma were assayed using a validated high performance liquid chromatography with UV-HPLC method. The assay was found to be sensitive and rapid enough to be easily applicable to human pharmacokinetic studies of PX.

The mean plasma concentration versus time profiles for PX after a single oral dose of PTX is shown in Figure 2. The pharmacokinetic parameters were calculated using non-compartmental analysis method, using WinNonlin ${ }^{\mathrm{TM}}$. They are summarized in Table 3. The plasma profile of PX was found to rise rapidly with an apparent $\mathrm{t}_{\text {max }}$ occurring at $0.784 \pm 0.406 \mathrm{~h}$ after oral administration of the test compared with the reference $(1.48 \pm 0.79)$ tablet. There was approximately a 19 fold difference in $\mathrm{C}_{\max }$ values of test and reference $(1260 \pm 910 \mathrm{ng} / \mathrm{mL}$ vs. $67.9 \pm 33.7$ $\mathrm{ng} / \mathrm{mL}) . \mathrm{AUC}_{0 \text {-inf }}$ in plasma were $1740 \pm 850 \mathrm{ng} . \mathrm{h} / \mathrm{L}$ and $1270 \pm 780$ ng.h/L. The elimination of PX was relatively fast with a $t_{1 / 2}$ of $1.70 \pm 1.25 \mathrm{~h}$ and $1.84 \pm 1.42 \mathrm{~h}$. The $\mathrm{t}_{1 / 2}$ values were found to vary widely; similar results were reported by Beerman et al., (1985) who obtained a mean $\mathrm{t}_{1 / 2}$ value of $3.43 \mathrm{~h}$. No significant change in $t_{1 / 2}$ was noted, which is what is expected from a linearly acting drug like PX. Also, pharmacokinetic parameters do not change with formulation. The results clearly show prolonged

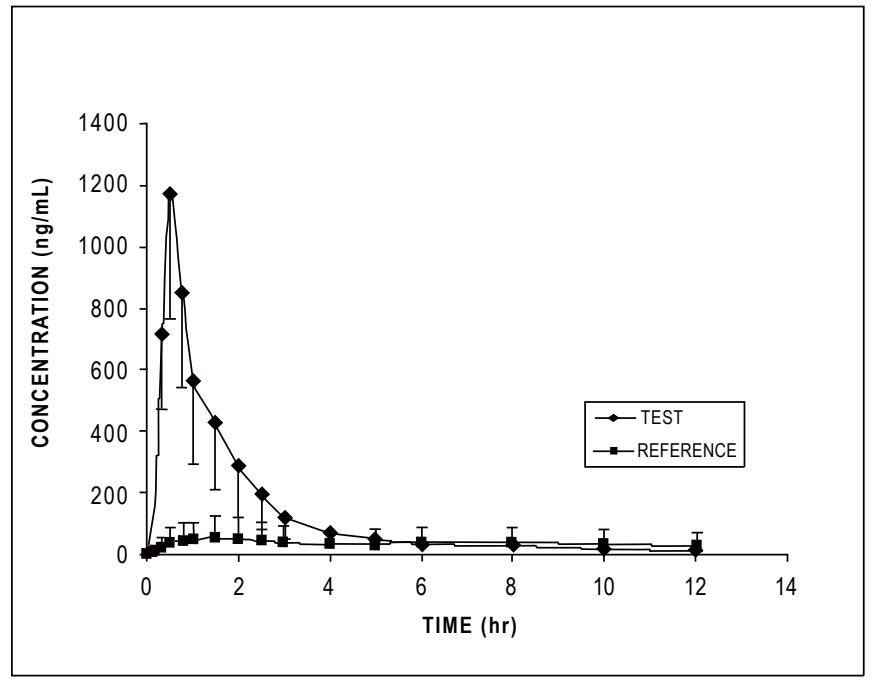

Figure 2:

\begin{tabular}{|l|l|l|}
\hline $\begin{array}{l}\text { Pharmacokinetic } \\
\text { Parameter }\end{array}$ & Test & Reference \\
\hline $\mathrm{AUC}_{0-12}(\mathrm{ng} . \mathrm{h} / \mathrm{L})$ & $1640 \pm 920$ & $439 \pm 190$ \\
\hline $\mathrm{AUC}_{0-\mathrm{inf}}(\mathrm{ng} . \mathrm{h} / \mathrm{L})$ & $1740 \pm 850$ & $1270 \pm 780$ \\
\hline $\mathrm{C}_{\max }(\mathrm{ng} / \mathrm{mL})$ & $1260 \pm 910$ & $67.9 \pm 33.7$ \\
\hline $\mathrm{t}_{\max }(\mathrm{h})$ & $0.784 \pm 0.406$ & $1.48 \pm 0.79$ \\
\hline$\lambda_{\mathrm{z}}\left(\mathrm{h}^{-1}\right)$ & $0.556 \pm 0.260$ & $0.495 \pm 0.240$ \\
\hline $\mathrm{t}_{1 / 2}(\mathrm{~h})$ & $1.70 \pm 1.25$ & $1.84 \pm 1.42$ \\
\hline $\mathrm{V}_{\mathrm{d}}(\mathrm{L})$ & $2.89 \pm 1.80$ & $8.05 \pm 4.20$ \\
\hline $\mathrm{Cl}(\mathrm{L} / \mathrm{h})$ & $350 \pm 270$ & $574 \pm 340$ \\
\hline
\end{tabular}

Table 3: Non-compartmental pharmacokinetic parameters for PX after single oral dose from healthy subjects $(n=12)$, (mean $\pm \mathrm{SD})$. 


\section{Journal of Bioequivalence \& Bioavailability - Open Access}

JBB/Vol.1 November-December 2009

plasma levels, without prolonged half-life. The clearance $(\mathrm{Cl} /$ $\mathrm{FF}^{*}$, clearance encompassing bioavailability) was $350 \pm 273$ and $574 \pm 340 \mathrm{~L} / \mathrm{h}$, for test and reference respectively. The distribution volume $\mathrm{V}_{\mathrm{d}}$ was low $(2.89 \pm 1.80 \mathrm{~L}$ and $8.05 \pm 4.20 \mathrm{~L})$.

It was shown that PX was rapidly cleared from plasma; it undergoes extensive first pass metabolism (Hinze et al., 1976; Smith et al., 1986). Oral bioavailability of PX tablet was found to be $20-30 \%$ (Beerman et al., 1985). Our in vivo study has shown that, the mean bioavailability of PX from CH-PX was not similar to that of the reference. The plasma profiles obtained from the reference were relatively constant, showing sustained release, but much lower $\mathrm{C}_{\max }$ than the test. They both also showed high variability and the test was not found to be bioequivalent with the reference at $90 \%$ level.

\section{Discussion}

$\mathrm{CH}$ is able to allow paracellular transport by opening the tight junctions of epithelial cells, but this absorbing enhancing effect is only possible in acidic environments (Illum, 1998). CH has a solubility with $\mathrm{pH}$ dependence and therefore might act as an absorption enhancer, rather than a release retardant, depending upon the media. According to our results, $\mathrm{CH}$ apparently played an important role for enhancing bioavailability of PX. This effect of $\mathrm{CH}$ might be caused by favouring the paracellular transport of PX.

$\mathrm{PX}$ is a water soluble compound and diffuses through the $\mathrm{CH}$ gel layer, when presented to the stomach. This gel layer occurrence is considered to be important for the PX release. It was visually observed that, the gel layer can form some barrier effect. At early stages, a stagnant gel layer controls the diffusion, but as time passes, the network of the gel starts to disintegrate and thus diffusion is facilitated. This mechanism was found to be responsible for zero order release in vitro. Under in vivo conditions, results showed that, the product has a fast release behavior, instead of a somewhat sustained release observed in vitro. Incidentally, $\mathrm{CH}$ has been in use to increase the permeation or absorption of drugs through nasal, buccal and intestinal mucosa (Aspden et al., 1996; Degim et al., 2003; Senel et al., 2000). The enhancing capability of $\mathrm{CH}$ is thought to be responsible for the opening of tight junctions of epithelial cell barriers (Kotze et al., 1998a; Kotze et al., 1998b). When the plasma concentrations were considered after administration, higher levels were observed with $\mathrm{PX}-\mathrm{CH}$ than reference. The intersubject variations were also observed in this study. It could be mainly due to the functioning of the gastrointestinal tract like gastric acid secretion, gastric emptying, gastrointestinal motility, etc.

Recently, $\mathrm{CH}$ and $\mathrm{CH}$ thiolated polymers were evaluated to modulate drug absorption by inhibition of intestinal Pglycoprotein $(\mathrm{P}-\mathrm{gp})$. The in vivo study showed that a delivery system based on thiolated $\mathrm{CH}$ significantly increased the oral bioavailability of P-gp substrate of rhodamine-123 (Föger et al., 2006a; Föger et al., 2006b). It has been previously reported that inhibition of efflux pumps by various compounds can lead to enhanced absorption of drugs across the intestine. Werle and Hoffer, (2006) demonstrated a P-gp inhibitory effect of thiolated $\mathrm{CH}$ on freshly excised guinea pig ileum. Therefore, enhancement of the systemic availability of PX may increase its available concentrations in the body by suppressing P-gp effluxtransporters.
PX is hepatically metabolized by hydroxylation and demethylation to six renally excreted metabolites (Smith et al., 1986). The presence of high test formulation PX levels may alter the mechanism of metabolizing enzymes by saturation, which may lead to increased bioavailability. On the other hand, PX is reduced extrahepatically to form an intermediate metabolite known as hydroxy-PX which may be converted back to parent compound or possibly be metabolized further (Mauro et al., 1988).

Pentoxifylline has a wider therapeutic range (1200-2000 mg/ day) in humans for oral application (Antignanai et al., 1989). In our study, each subject was administered $400 \mathrm{mg}$ of PX orally as $\mathrm{PX}-\mathrm{CH}$ and the reference for bioavailability evaluation. In our further clinical part of the study, we also examined the hematological effects of the test and reference formulations in the same 12 healthy volunteers, who received $400 \mathrm{mg}$ of PX(twice a day) for 10 days. Although no bioavailability studies were carried out at steady state, it was hematologically observed. The test and reference formulations were not found to be similar in this study at single dose level, however the commercial product and the new formulation of $\mathrm{CH}$ tablet were clinically well tolerated and similar hematological effects were observed at steady state, as reported in our previous paper (Yamac et al., 2000). We concluded that enhancement in the bioavailability of PX would suggest that $\mathrm{CH}$ could be used to improve oral bioavailability of PX. PX was also well tolerated when administered as a PX-CH matrix tablet formulation. It could be used without observing any clinical problems.

\section{Acknowledgments}

This study was supported by grants from TUBÝTAK, Turkish Scientific and Technical Research Council, Grant no. SBAG1850 and from Gazi University Research Fund, Grant no. EF/ 0297-01. The authors would like to thank Sanofi Aventis Co.,Turkey, for supplying pentoxifylline and Dainichiseika Mfg.Co. for supplying the chitosan.

\section{References}

1. Agabeyoglu I, Teksin ZS (2000) The validation of high-performance liquid chromatographic(HPLC) method of pentoxifylline for pharmaceutic/bioequvalence studies. Acta Pharm.Turcica. XLII 105.

2. Antignanai PL, Todini AR, Saliceli F (1989) Results of clinical, laboratory and haemorheological investigations of the use of pentoxifylline in high doses. Pharmatherapeutica 5: 50-56. » Pubmed

3. Aspden TJ, Illum L, Shaugrud O (1996) Chitosan as a nasal delivery system: Evaluation of insulin absorption enhancement and effect on nasal membrane integrity using rat model. Eur J Pharm Sci 4: 23-31.» CrossRef » Google Scholar

4. Aungst BJ (2000) Intestinal permeation enhancer. J Pharm Sci 89: 429-442. »CrossRef » Pubmed » Google Scholar

5. Beermann B, Ings R, Mansby J, Chamberlain J, McDonald A (1985) Kinetics of intravenous and oral pentoxifylline in healthy subjects. Clin Pharmacol Ther 37: 25-28. „CrossRef » Pubmed » Google Scholar

6. Degim IT, Acarturk F, Erdogan D, Lortlar ND (2003) 


\section{Journal of Bioequivalence \& Bioavailability - Open Access \\ JBB/Vol.1 November-December 2009}

Transdermal administration of bromocriptine. Biol Pharm Bull 26: 501-505.» CrossRef » Pubmed » Google Scholar

7. Felt O, Buri P, Gurny R (1988) Chitosan: A unique polysaccharide for drug delivery. Drug Dev Ind Pharm 24: 979-993. "CrossRef » Pubmed " Google Scholar

8. Föger F, Schmitz T, Bernkop-Schnürch A (2006a) In vivo evaluation of an oral delivery system for P-gp substrates based on thiolated chitosan. Biomaterials 27: 4250-5. »CrossRef » Pubmed » Google Scholar

9. Föger F, Hoyer H, Kafedjiiski K, Thaurer M, BernkopSchnürch A (2006b) In vivo comparison of various polymeric and low molecular mass inhibitors of intestinal P-glycoprotein. Biomaterials 27: 5855-60. »CrossRef » Pubmed " Google Scholar

10. Hinze HJ, Grigoleit HG, Rethy B (1976) Bioavailability and pharmacokinetics of pentoxifylline from "Trental 400" in man. Pharmatherapeutica 1: 160-171.

11. Illum L (1998) Chitosan and its use as a pharmaceutical excipient. Pharm Res 55: 1326-1331.» CrossRef » Pubmed " Google Scholar

12. Inoyatov N, Celebi N, Acarturk F (1998) Preparation and evaluation of a prolonged release pentoxifylline tablet with chitosan. Pharm Ind 60: 472-475.» CrossRef » Google Scholar

13. Kotze AF, Lueben HL, de Boer AG, Verhoef JC, Junginger HE (1998b) Chitosan for enhanced intestinal permeability: Prospects for derivatives soluble in neutral and basic environments. Eur J Pharm Sci 7: 145-151.

14. Kotze AF, Thanou M, Verhoef CJ, Junginger HE (1998a) Chitosan and $\mathrm{N}$-trimethyl chitosan chloride as absorption enhancers for nasal and rectal delivery of insulin. Proceed Int Symp Control Rel Bioactive Mater 25: 179-180.

15. Kristl J, Smid-Korbar J, Stuc E, Schara M, Rupprecht H (1993) Hydrocolloids and gels of chitosan as drug carriers. Int J Pharm 99: 13-19. » CrossRef » Google Scholar

16. Kumar MR (1998) A review of chitin and chitosan applications, reactive and functional polymers. Reactive \& Functional Polymers 46: 1-27.
17. Mauro VF, Mauro LS, Hageman JH (1988) Alteration of pentoxifylline pharmacokinetics by cimetidine. J Clin Pharmacol 28: 649-54.» CrossRef » Pubmed » Google Scholar

18. Nigalaye P, Adusumilli P, Bolton S (1990) Investigation of prolonged drug release from matrix formulations of chitosan. Drug Dev Ind Pharm 16: 449-467. » CrossRef » Google Scholar

19. Senel S, Kremer MJ, Kas S, Wertz PW, Hýncal AA, et al. (2000) Enhancing effect of chitosan on peptide drug delivery across buccal mucosa. Biomaterials 21: 2067 -2071. »CrossRef » Pubmed » Google Scholar

20. Smith RV, Waller ES, Doluisio JT, Bauza MT, Puri SK, et al. (1986) Pharmacokinetics of orally administered pentoxifylline in humans. J Pharm Sci 75: 47-52. »CrossRef » Pubmed » Google Scholar

21. Teksin ZP, Aðabeyoðlu IT, Yamac K (2000) Comparison of Bioavailability of a Chitosan Tablet Formulation of Pentoxifylline $_{\text {th }}$ with a Commercial Product (Trental). Proceed of the 27 Int'l Symp Control Rel Bioact Mater 7-13.

22. Thanou M, Verhoef JC, Junginger HE (2001b) Oral drug absorption enhancement by chitosan and its derivatives. Adv Drug Deliv Rev 52: 117-126. » CrossRef » Pubmed » Google Scholar

23. Thanou M, Verhoef JC, Junginger HE (2001a) Chitosan and its derivatives as intestinal absorption enhancer. Adv Drug Deliv Rev 50: 91-101. »CrossRef » Pubmed » Google Scholar

24. Ward A, Clissod P (1987) Pentoxifylline: A review of its pharmacokinetic properties and its therapeutic efficacy. Drugs 34: 50-97.» Pubmed » Google Scholar

25. Werle M, Hoffer M(2006) Glutathione and thiolated chitosan inhibit multidrug resistance P-glycoprotein activity in excised small intestine. J Cont Rel 111: 41-46.» CrossRef » Pubmed » Google Scholar

26. Yamac K, Kaptan K, Beyan C, Teksin ZS, Agabeyoglu Ý, et al. (2000) Comparison of hematological effects of a sustained release chitosan formulation of pentoxifylline with a commercial product. Arzneim Forsch/Drug Res 50: 827-831. »CrossRef » Pubmed » Google Scholar 